\title{
Michel Foucault e a teoria do poder
}

\author{
JOSÉ AUGUSTO GUILHON ALBUQUERQUE
}

RESUMO: Mais do que a teoria do poder, Foucault propõe regras ou cautelas metodológicas. Diferentemente das concepções correntes, Foucault pretende explicar o poder sem o rei como sua fonte e natureza. Depois de comparar diferentes concepções correntes de poder, mostrando sua dependência da noção de um soberano, define-se o poder em Foucault como uma relação assimétrica que institui a autoridade e a obediência, e não como um objeto preexistente em um soberano, que o usa para dominar seus súditos. Para ilustrar o conceito foucaultiano de poder, comenta-se uma situação atual da política nacional.

eria, certamente, excessivo falar em teoria do poder tratando-se de Foucault. Ele rejeitava a idéia de Teoria com T maiúsculo, à qual atribuía uma função de poder muito mais do que de instrumento de conhecimento. Quando trata de maneira mais sistemática do poder, Foucault prefere falar em "precauções metodológicas", "regras", etc., e nunca em teoria.

Portanto, quando eu falar em teoria do poder em Foucault, trata-se na verdade de um conjunto de regras metodológicas a partir das quais se pode formular hipóteses, e que configuram muito mais um modo de abordagem e um objetivo de pesquisa do que uma teoria completa. Embora esteja, de muitos pontos de vista, nas antípodas do chamado empirismo anglo-saxão, Michel Foucault nos legou muito mais um "programa de pesquisa" no sentido americano da expressão, do que uma teoria ou um paradigma no sentido europeu e particularmente francês.

Creio que uma boa maneira de abordar o enfoque foucaultiano do

\section{UNITERMOS:}

Foucault, teoria do poder, autoridade, poder como relação assimétrica.
Professor do Departamento de Ciência Política da FFLCHUSP 
poder é uma espécie de bravata intelectual do $\mathrm{I}^{\mathrm{o}}$ volume da sua História $\mathrm{da}$ sexualidade; A vontade de Saber, onde ele se propõe como missão construir uma concepção do desejo sem a lei e do poder sem o rei. Trata-se de uma concepção totalmente revolucionária do poder que, embora seja coerente com uma parte significativa da tradição do pensamento político ocidental - refirome especificamente à tradição maquiaveliana, mas não pretendo desenvolver este ponto - rompe não apenas com as características habitualmente atribuídas ao poder, seus efeitos e modos de funcionamento, mas essencialmente com a maneira como concebemos sua natureza.

Façamos um exercício para pensar num poder sem o rei, isto é, sem pressupor que o poder emana de uma fonte que o detém e pode deixá-lo fluir. Tentemos pensar no poder sem uma pessoa, autoridade, ou instituição que não apenas o possui mas determina sua natureza, seus limites e seu modo de funcionamento.

Inútil: tudo o que podemos pensar é em recursos de poder, que só são considerados como tais quando podem ser utilizados por pessoas, grupos, entidades, instituições; tudo o que podemos pensar é em prerrogativas atribuídas a autoridades ou entidades; tudo o que podemos pensar é em coisas possuídas por uns e das quais outros são despossuídos, é impossível pensar o poder sem o rei - ou sem súditos, o que vem a dar no mesmo - na nossa concepção corrente, que Foucault chama de concepção do poder-soberania.

Experimentemos algumas definições simples e mais correntes do poder. "O poder é a capacidade que tem o Estado para obter obediência dos seus súditos". É impossível dar sentido a esta frase sem colocar alguém na posição do rei, no caso, o Estado. Podemos substituir Estado por autoridade, líder, instituição, mas sempre o poder será alguma coisa que pertence - ou é possuída - por alguma entidade.

Também podemos substituir capacidade de obter obediência por capacidade de submeter, por prerrogativa de impor, por probabilidade de influenciar o comportamento - esta última uma definição mais sociológica, weberiana - é inútil: sempre se supõe um rei, uma entidade que submete, que impõe, que influencia.

Vejamos esta definição de poder nacional da Escola Superior de Guerra: "Poder Nacional é a capacidade de que a nação, decidida, dispõe para conquistar e manter seus objetivos". A entidade que aqui substitui o rei é a nação, e não por acaso, porque o Estado nacional é o substituto do rei absolutista, o modelo mais acabado do poder-soberania segundo Foucault. A frase é rigorosamente equivalente à anterior, embora contenha um ator e um objeto, $\mathrm{e}$ não dois atores. Aqui, poder é a capacidade de $A$ para obter $X$, enquanto na frase anterior poder é a capacidade de A para agir sobre B, ou para obter X de B.

Podemos substituir poder nacional e nação por poder pessoal $\mathrm{e}$ pessoa, e teremos, poder pessoal é a capacidade de que a pessoa, decidida, dispõe para obter seus objetivos, ou para obter algo de outra pessoa, entidade ou grupo de pessoas. 
Na concepção corrente do poder o rei (A) sempre estará presente, assim como seu simétrico, o súdito (B). E poder sempre será um objeto que passa do rei para o súdito ou que o rei retira do súdito.

Passemos a uma noção mais sofisticada: o poder é o conjunto de recursos, de natureza psicológica, material ou econômica, existentes na sociedade, que os indivíduos põem a serviço de uma autoridade suprema, para manter a ordem pública. É esta a noção que corresponde ao conceito de poder em Thomas Hobbes, uma das vertentes do pensamento político moderno. Aqui, de novo, aparecem os mesmos elementos: o poder é um objeto (um conjunto de recursos) possuído pelo rei (a autoridade suprema) e oferecido por seus súditos (os indivíduos da sociedade). Hobbes se encarrega de dar concretude à entidade que detém o poder chamando-a Leviatã.

Curiosamente, mas não por acaso, o Leviatã é frequientemente retratado na figura de um rei. Uma imagem muito conhecida retrata o Leviatã como um rei guerreiro, cujo corpo é composto por uma infinidade de corpos de seus súditos. A significação é clara: o poder do rei é a soma dos poderes de seus simétricos súditos. Mais do que a soma, a incorporação de seus súditos, no sentido literal da palavra. O poder é uma espécie de corpo místico do rei.

O que dá sentido à frase é a incorporação, incorporação dos recursos dos indivíduos no poder do rei. Para que haja incorporação é preciso que os indivíduos, ou seus corpos, para manter a metáfora do Leviatã, sejam previamente investidos de poder (embora sob a forma, ainda, de recursos materiais e espirituais), e que o rei esteja disponível para ser investido de poder. Alguma pessoa ou entidade deve existir previamente, embora destituída de poder e de autoridade, isto é, da condição de rei.

Fim do exercício: está suficientemente ilustrado o fato de que não é possível, nas concepções dominantes de poder no pensamento político moderno, pensar o poder sem aqueles que o possuem.

Isto se deve a que a concepção moderna do poder é uma representação do funcionamento do poder na transição para o poder moderno. É uma representação do poder-soberania na acepção de Foucault, isto é, do modo de funcionamento do poder na transição das monarquias clássicas para as monarquias absolutas, na formação do Estado moderno.

O absolutismo se caracterizou, entre outras coisas, por uma grande concentração de recursos de poder na monarquia. $\mathrm{O}$ modo de funcionamento do poder se caracterizava por um processo de contração de recursos e forças no centro, para distender-se em direção a alvos periféricos, seguido de nova contração em direção ao centro.

Tratava-se de um poder de ação intermitente, sempre visando esmagar ou aniquilar seu alvo. Juntar e recolher recursos, distender e aniquilar o objetivo, recolher e juntar novos recursos, eis a sequiência lógica do funcionamento do poder-soberania.

Daí a imagem do poder com três componentes: o centro que concentra poder, o rei; a periferia sobre a qual se desencadeia o poder, o súdito; a 
força material que se concentra e se desencadeia, o poder propriamente dito. Todos preexistindo em sua própria essência: o poder estava lá, só não estava concentrado; o rei estava lá, só não concentrava poder; o alvo estava lá, só não estava submetido ao poder-soberania.

Só que essa representação nos faz esquecer que o rei estava lá, mas não o monarca absoluto. A monarquia absoluta é o resultado, não o pressuposto desse processo. O súdito estava lá, mas não como súdito submetido ao poder monárquico, e sim como vassalo de soberanias competitivas e sobrepostas, e sim como sujeito de foros e privilégios. O poder estava lá, mas sua concentração mesma nas mãos do monarca muda-lhe a natureza e o processo de funcionamento.

Em suma, o poder-soberania, esse aglomerado de recursos que se concentra e se desencadeia para esmagar seu alvo não é uma invenção do monarca absoluto. A monarquia absoluta é que é uma invenção de um poder que funciona concentrando-se para submeter seus súditos.

Se reconsiderarmos agora a noção hobbesiana de poder, base de toda a concepção moderna, tanto absolutista como democrática de poder, poderemos encará-la com outros olhos. Agora á mais factível dar-lhe significado sem o par simétrico reis-súditos. Se retirarmos os atores de cena, isto é, tanto o corpo majestático do rei, quanto a infinidade de corpos que lhe dão corpo, o que fica?

Fica o conjunto de recursos de natureza psicológica, material e econômica existentes na sociedade, (que os indivíduos) põem a serviço (de uma autoridade suprema) para manter a ordem política.

$\mathrm{O}$ que temos aqui? Primeiro, o conjunto de recursos existentes na sociedade quer dizer tudo e não quer dizer nada. O poder pode ser tudo e qualquer coisa. Não são os recursos de poder que o definem. O poder não são coisas ou objetos. O que chamamos de recursos ou instrumentos de poder só dão lugar ao fenômeno do poder quando são postos a serviço de uma autoridade suprema, para manter a ordem política.

Segundo, além de objetos, que podem ser tudo e nada, temos uma relação e uma meta. A relação é a que estabelece, de um lado, indivíduos, de outro, autoridade: pôr a serviço, conferir, erigir, legitimar, alienar.

Quanto à meta, isto é, manter a ordem política, prefiro falar em meta a objetivo, para evitar qualquer conotação teleológica e, portanto, a noção de uma consciência desejante previamente existente. Eu diria que essa meta define a natureza da relação de poder.

Pois bem, para pensar o poder sem o rei, terei que pensá-lo como uma relação assimétrica (pôr a serviço de, conferir, alienar a, dar legitimidade, prestar obediência a, etc.) que institui dois pólos, um que exerce, outro que é objeto do poder. A natureza dessa relação assimétrica é sua subordinação à manutenção da ordem política.

Creio que isto nos permite compreender agora a teoria do poder em Foucault. Ele opõe uma concepção do poder como um conjunto de forças 
materiais que se concentra no centro da sociedade, e se irradia de forma intermitente em direção à periferia, mediante espasmos que se desencadeiam para submeter aos bons súditos e esmagar os insubmissos; que funciona negativamente, por confisco e por coleta; a uma concepção do poder como relação assimétrica entre indivíduos, entre grupos, que se irradia da periferia para o centro, de baixo para cima, que se exerce permanentemente, dando sustentação à autoridade, e que funciona positivamente, dinamizando, incrementando as forças e recursos existentes.

Assim, em vez de coisas, o poder é um conjunto de relações; em vez de derivar de uma superioridade, o poder produz a assimetria; em vez de se exercer de forma intermitente, ele se exerce permanentemente; em vez de agir de cima para baixo, submetendo, ele se irradia de baixo para cima, sustentando as instâncias de autoridade; em vez de esmagar e confiscar, ele incentiva e faz produzir.

Agora que estamos familiarizados com a teoria do poder em Foucault ou, se quiserem, com as regras e precauções metodológicas propostas por Foucault para estudar o poder, podemos dedicar estes minutos finais a um pouco de masturbação sociológica. Perdoem-me a expressão, mas é uma homenagem a nossos governantes, uma vez o Presidente domina a Ciência Política, mas o governo prefere agir por instinto. Quanto a mim, prefiro infinitamente masturbações sociológicas sobre as relações de poder, às ruminações de senso comum sobre a "vontade política".

Se estamos de acordo sobre a possibilidade de pensar o poder sem o rei, como propôs Foucault, não há lugar, nas relações de poder, para a vontade política. Sem o rei para expressar e exercer a vontade como sujeito, sem os súditos para cumprí-la como objeto, o poder não conhece a vontade de quem quer que seja.

Se o poder se sustenta de baixo para cima, ao contrário de se originar de cima para baixo, quanto mais alto na hierarquia de poder, menor a autonomia do indivíduo para alterar as redes de poder na sociedade. Nesse sentido, a ação individual do chefe de governo é menos decisiva do que a do mestre-escola. Foi por isso que todos os Estados modernos forjaram sua nação através da instrução pública, e não pela vontade do rei.

Pensar que a vontade pode apertar um botão em Brasília e haverá qualquer modificação, para melhor ou para pior na ponta do balcão, nos confins do Amapá, é de uma ingenuidade tal, que espanta. Para que deixe de faltar mercurocromo num pronto-socorro, para que se distribuam boas merendas, boas cartilhas e um pouco de instrução numa sala de aula, são mais importantes as relações de poder entre o pessoal mais humilde dessas agências governamentais e a clientela local do que os devaneios de qualquer ministro.

A capacidade de atuação, positiva ou negativa de um chefe de governo depende de sua relação com as lideranças políticas; estas, por sua vez, têm seu raio de ação traçado de acordo com as relações entre partidos e lideranças, que dependem, por sua vez, do sistema eleitoral. Os acordos do gover- 
ALBUQUERQUE, José Augusto Guilhon. Michel Foucault e a teoria do poder. Tempo Social; Rev. Sociol. USP, S. Paulo, 7(1-2): 105-110, outubro de 1995.

no com as lideranças deixam de se cumprir não apenas porque as lideranças prefiram trair, mas porque os partidos não as seguem. E os partidos não seguem as lideranças porque seria irracional fazê-lo, já que o sistema eleitoral não pune a irresponsabilidade política, e assim é porque o sistema eleitoral obriga o eleitor a dar um cheque em branco ao eleito.

Portanto, se fosse eu, estaria menos preocupado em ruminar sobre a vontade política dos governantes, do que com a relação irresponsável que o sistema eleitoral estabelece entre eleitores e eleitos. Porque se o resultado do voto é irrelevante, o eleitor também se torna irresponsável. Já que o voto é um cheque em branco, é melhor limitar o prejuízo, e votar no dentista do bairro. Pelo menos é certo que não fará mal nenhum ao País, porque sequer será eleito.

Nosso passaporte para o mundo das democracias estáveis, da inflação baixa, dos governos confiáveis, até agora só tem um visto de turismo que é o Plano Real. O visto definitivo só virá quando começarmos a mexer no voto e fizermos dele, não um cheque em branco, mas um vínculo de poder.

Recebido para publicação em abril/1995

UNITERMOS:

Foucault, theory of power, authority, power as an asymmetric relation
ABSTRACT: Power is defined in Michel Foucault's conceptions as a set of methodological cautions rather than a complete theory. As oposed to current modern conceptions, Foucault deals with a definition of power that does not include "the king" as a source and a center from where power is supposed to flow. After comparing different modern current definitions of power, emphasizing their need for the impersonation of a "king" to explain power, Foucault's definition is presented as an assymetrical relationship. Rather than two preexisting actors, one full of power and other powerless, which would explain authority and obedience, that relantionship is presented as resulting in the existence of two political actors, a "sovereign" and subject. As an illustration, a current situation in Brazilian politics is commented in Foucault's terme. 